\title{
Thromboxane B2
}

National Cancer Institute

\section{Source}

National Cancer Institute. Thromboxane B2. NCI Thesaurus. Code C107560.

An eicosanoid and biologically inactive metabolite of thromboxane A2. Thromboxane B2

is released during anaphylaxis. As thromboxane A2 has a short half-life, the levels of

thromboxane B2 can be used to indirectly measure the production of thromboxane A2 